\title{
Elastic Behavior of Lay-Ups Angles of Laminated Composite Beam with Material Property Grading
}

\author{
Saeed Asiri
}

\begin{abstract}
The article discusses the study of Vibration Analysis of Generally layered Graphite-Epoxy with lay-up $\left[30^{\circ} / 50^{\circ} / 30^{\circ} / 50^{\circ}\right]$. The finite element method is utilized in the study, to analyze the effect of lay-up on the natural frequency and comparing the results with the article[1]. Method: The study is done using Ansys. Graphite-epoxy is considered for the study. The model is prepared from SHELL 281 element which is well-suited for composite shells and sandwiched construction. The accuracy in modeling composite shells is governed by the first-order MindlinReissner shell theory. The element has 8 nodes with 6 degrees of freedom at each node translations in the $x, y$, and $z$ axes, and rotations about the $x, y$, and z-axes respectively. Finding: The study concludes that the values of natural frequency decreased when increased the difference between angles of lay-up. Novelty/Applications: Vibration Analysis study has been done in aspects, like sandwiched beam in which different materials are sandhwiched in a layer by layer fashion. Many studies also covers composite material with lay-up in great detail, but there is acute study about the comparision of the different lay-up angles at given boundary condition. These articles cover the same at a greater extent, and conclude that the strength and capacity of composite beams can be enhanced not only by blending composites together, but also giving importance to the arrangement of layers of composite materials.
\end{abstract}

Keywords: Vibration Analysis, Lay-up, Sandwiched Beam, Finite Element Method

\section{INTRODUCTION}

Composites materials have been in use since ages and it is can not be claimed as a very recent development. Egyptians used Cartonnage and layers of linen or papyrus soaked in plaster to make death masks, Mongols developed bows combining animal horn and bamboo. Composite materials are playing a major role in designing structural components of mechanical, aerospace, and civil engineering. Composites are considered due to their outstanding engineering property including high strength and stiffness to weight ratios. A composite is a structural material made from two or more constituent materials with different physical and chemical properties, when combined produces a material with new properties that cannot be accomplished with either component acting alone.

Manuscript received on June 30, 2021

Revised Manuscript received on July 04, 2021.

Manuscript published on July 30, 2021.

* Correspondence Author

Saeed Asiri*, Associate Professor, Department of Mechanical Engineering, College of Engineering, King Abdulaziz University, Saudi Arabia.

(C) The Authors. Published by Blue Eyes Intelligence Engineering and Sciences Publication (BEIESP). This is an open access article under the CC BY-NC-ND license (http://creativecommons.org/licenses/by-nc-nd/4.0/)
The constituent that is embedded is called the matrix and the other constituent is called the reinforcing phase In general, the reinforcing phase is the major load-carrying member, while the matrix keeps the reinforcing phase in the preferred orientation and location which provide the desired elastic connection through the correct ply-angle selection. These structural elements are often subject to dynamic loads under complex environmental conditions, which require the mathematical model to be precisely formulated to analyze its vibrational characteristics. Abramovich [2] studied laminated composite beams considering some boundary conditions. Teoh and Huang [3] provided a theoretical study of vibration of composite beams with solid cross-sections. The numerical results are given by Abramovich and Livshits[4] for free laminated vibration cross-ply composite beams. Teboub and Hajela [5] used FSDT to analyze the free vibration of general composite beams. [6] presented theories for the structural analysis of shear deformable isotropic of laminated beams. Marur and Kant [7] presented the higher-order model for the transient dynamic analysis of composite and sandwich beams. Lee [8] presented the natural frequencies for a laminated beam with delimitations. Jun $\mathrm{Li}$ et al [9] compared the various theories on shear deformation in laminate composite beams with general layups for free vibration. A study of the development of the vibration analysis for the composite beams was compiled by Kapania and Raciti [10]. Chen and Yang [11] worked out the free vibration analysis of symmetrically laminated beams based on the FSDBT using the finite element method. Teh and Huang [12] developed two finite element models based on the FSDBT for the prediction of natural frequencies of the fixed-free beams with general orthotropy. In this study, natural frequencies of composite materials are predicted by the finite element method and the effect of layup angles of composite materials on the natural frequency at different boundary conditions. Natural frequency is one of the most important parameters or properties of any system. Natural frequency value determines the functionality of the system, its performances, and its life cycles thus, determination of the exact frequency of the system is of utmost importance.

\section{PROBLEM DESCRIPTION}

A laminated composite beam, as shown in Fig 1, is considered in this study. The laminated beam is assumed to be created of an orthotropic layer and the layers are oriented at different angles, as shown in Fig 2. The laminated beam studied has a length of $L=0.381 \mathrm{~m}$, $\mathrm{a}$ width of $\mathrm{b}=25.4 \times 10$ ${ }^{3} \mathrm{~m}$, and a thickness of $\mathrm{h}=25.4 \times 10-^{3} \mathrm{~m}$.

Published By:

Blue Eyes Intelligence Engineering 


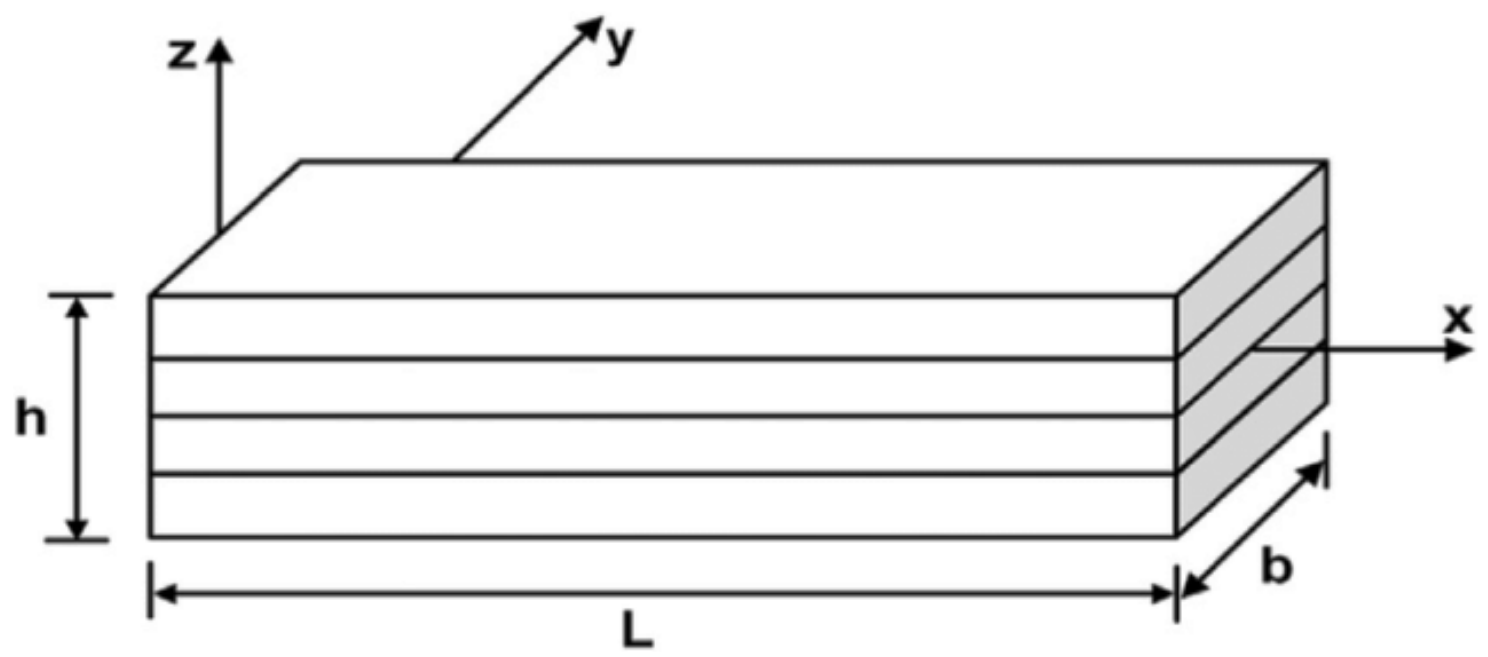

Fig 1. Geometry of a laminated composite beam

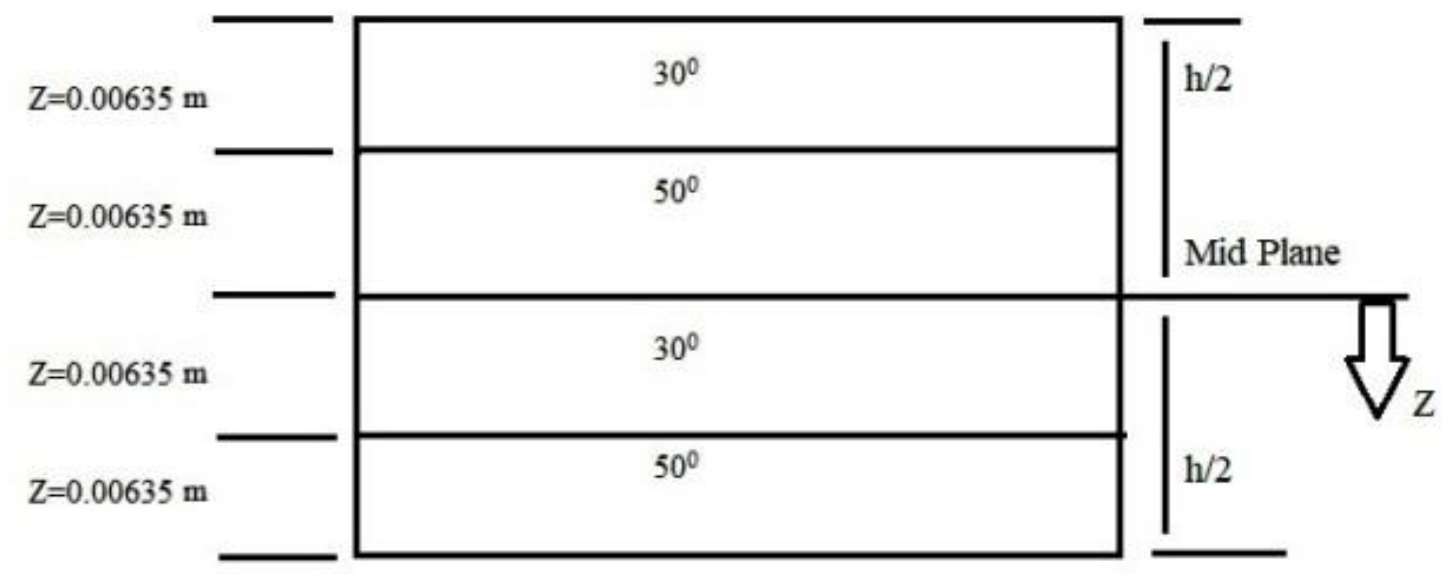

Fig 2. Lay-up of laminated beam

The material used for the beam is graphite-epoxy with lay-up $\left[30^{\circ} / 50^{\circ} / 30^{\circ} / 50^{\circ}\right]$, the mechanical properties of the layer are as follows:

$$
\begin{gathered}
\mathrm{E}_{1}=144.8 \times 10^{09} \mathrm{~Pa} \quad v_{12}=0.3 \mathrm{G}_{12}=4.14 \times 10^{09} \mathrm{~Pa} \quad \rho=1389.23 \mathrm{~kg} / \mathrm{m}^{3} \\
\mathrm{E}_{2}=9.65 \times 10^{09} \quad \mathrm{~Pa} \quad v_{13}=0.3 \mathrm{G}_{13}=3.45 \times 10^{09} \mathrm{~Pa} \\
\mathrm{E}_{3}=9.65 \times 10^{09} \mathrm{~Pa}_{23}=0.01 \quad \mathrm{G}_{23}=4.14 \times 10^{09} \mathrm{~Pa}
\end{gathered}
$$

Where $E_{1}$ is longitudinal Young's modulus. $E_{2}$ is transverse Young's modulus. $v_{12}$ is Poisson's ratio in the XY direction. $v_{13}$ is Poisson's ratio in the $\mathrm{XZ}$ direction. $v_{23}$ is Poisson's ratio in the $\mathrm{YZ}$ direction. $\mathrm{G}_{12}$ is the shear modulus in the $X Y$ direction. $G_{13}$ is the shear modulus in the $X Z$ direction $G_{23}$ is the shear modulus in the $Y Z$ direction and $\rho$ is density. Results have been used by 30 finite element mesh and three different boundary conditions including the Clamped-Clamped (C-C), Clamped-Simply supported (CS), and Simply supported-Simply supported (S-S).

\section{ANALYTICAL ANALYSIS}

This section has analytical analysis; equations and values of [C], [S], [C ], [T], [Q], [A], [B] and [D]. All calculations done by Ansys ACP in this section. To calculate stiffness matrix [C] and compliance matrix [S].

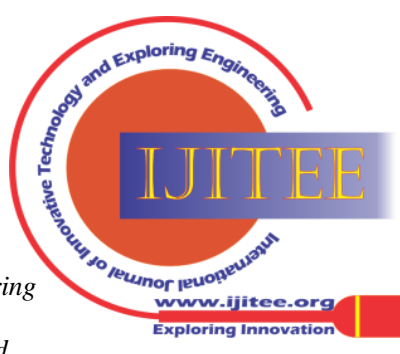




$$
[\mathrm{S}]=\left[\begin{array}{cccccc}
S 11 & S 12 & S 13 & 0 & 0 & S 16 \\
S 21 & S 22 & S 23 & 0 & 0 & S 26 \\
S 31 & S 32 & S 33 & 0 & 0 & S 36 \\
0 & 0 & 0 & S 44 & S 45 & 0 \\
0 & 0 & 0 & S 54 & S 55 & 0 \\
S 61 & S 62 & S 63 & 0 & 0 & S 66
\end{array}\right]
$$

By utilizing equation (1) \& (2), we get these values of Compliance and Stiffness Matrices:

$$
\begin{gathered}
{[S]=\left[\begin{array}{cccccc}
0.0069 & -0.0021 & -0.0021 & 0 & 0 & 0 \\
-0.0021 & 0.1036 & -0.0010 & 0 & 0 & 0 \\
-0.0021 & -0.0010 & 0.1036 & 0 & 0 & 0 \\
0 & 0 & 0 & 0.2899 & 0 & 0 \\
0 & 0 & 0 & 0 & 0.2415 & 0 \\
0 & 0 & 0 & 0 & 0 & 0.2415
\end{array}\right]} \\
{[C]=\left[\begin{array}{cccccc}
1.4658 & 0.0296 & 0.0296 & 0 & 0 & 0 \\
0.0296 & 0.0971 & 0.0016 & 0 & 0 & 0 \\
0.0296 & 0.0016 & 0.0971 & 0 & 0 & 0 \\
0 & 0 & 0 & 0.0345 & 0 & 0 \\
0 & 0 & 0 & 0 & 0.0414 & 0 \\
0 & 0 & 0 & 0 & 0 & 0.0414
\end{array}\right]}
\end{gathered}
$$

Transformation matrix $[\mathrm{T}]$, stiffness matrix $[\overline{\mathrm{C}}]$, and angle $\left[30^{\circ} / 50^{\circ} / 30^{\circ} / 50^{\circ}\right]$. To get [T], [C ], and [Q] matrixes reduced stiffness matrix [Q] need to be calculated for each used below equations:

$$
\begin{gathered}
{[\mathrm{T}]=\left[\begin{array}{cccccc}
\operatorname{Cos}^{2} \theta & \operatorname{Sin}^{2} \theta & 0 & 0 & 0 & -\operatorname{Sin} 2 \theta \\
\operatorname{Sin}^{2} \theta & \operatorname{Cos}^{2} \theta & 0 & 0 & 0 & \operatorname{Sin} 2 \theta \\
0 & 0 & 1 & 0 & 0 & 0 \\
0 & 0 & 0 & \operatorname{Cos} \theta & \operatorname{Sin} \theta & 0 \\
0 & 0 & 0 & -\operatorname{Sin} \theta & \operatorname{Cos} \theta & 0 \\
\operatorname{Sin}^{2} \theta \operatorname{Cos}^{2} \theta & -\operatorname{Sin}^{2} \theta \operatorname{Cos}^{2} \theta & 0 & 0 & 0 & \operatorname{Cos}^{2} \theta-\operatorname{Sin}^{2} \theta
\end{array}\right]} \\
{\left[\overline{C]}=[T][C][T]^{T}\right.}
\end{gathered}
$$

(4)

Where $[\mathrm{T}]^{\mathrm{T}}$ is the transpose of $[\mathrm{T}]$.

$$
\begin{aligned}
& {\left[\begin{array}{c}
\sigma_{x} \\
\sigma_{y} \\
\sigma_{x y}
\end{array}\right]=\left[\begin{array}{lll}
\overline{\mathrm{Q}}_{11} & \overline{\mathrm{Q}}_{12} & \overline{\mathrm{Q}}_{16} \\
\overline{\mathrm{Q}}_{21} & \overline{\mathrm{Q}}_{22} & \overline{\mathrm{Q}}_{26} \\
\overline{\mathrm{Q}}_{16} & \overline{\mathrm{Q}}_{26} & \overline{\mathrm{Q}}_{66}
\end{array}\right]\left[\begin{array}{c}
\varepsilon_{x} \\
\varepsilon_{y} \\
\gamma_{x y}
\end{array}\right]} \\
& \bar{Q}_{11}=Q_{11} c^{4}+Q_{22} \mathrm{~s}^{4}+2\left(Q_{12}+Q_{66}\right) \mathrm{s}^{2} \mathrm{c}^{2} \\
& \bar{Q}_{12}=\left(Q_{11}+Q_{22}+4 Q_{66}\right) \mathrm{s}^{2} \mathrm{c}^{2}+Q_{12}\left(\mathrm{c}^{4}+\mathrm{s}^{4}\right) \\
& \bar{Q}_{22}=Q_{11} \mathrm{~s}^{4}+Q_{22} \mathrm{c}^{4}+2\left(Q_{12+} Q_{66}\right) \mathrm{s}^{2} \mathrm{c}^{2} \\
& \bar{Q}_{16}=\left(Q_{11}-Q_{22}-2 Q_{66}\right) \mathrm{c}^{3} \mathrm{~s}-\left(Q_{22}-Q_{12}-2 Q_{66}\right) \mathrm{s}^{3} \mathrm{c} \\
& \bar{Q}_{26}=\left(Q_{11}-Q_{22}-2 Q_{66}\right) \mathrm{cs}^{3}-\left(Q_{22}-Q_{12}-2 Q_{66}\right) \mathrm{c}^{3} \mathrm{~s}
\end{aligned}
$$

Where $\mathrm{s}=\sin \theta$, and $\mathrm{c}=\cos \theta$.

$$
\mathrm{Q}_{11}=\frac{E_{1}}{1-\mathrm{v}_{21} \mathrm{v}_{12}}
$$

$\mathrm{Q}_{11}=\frac{E_{2}}{1-v_{21} \mathrm{v}_{12}}$

$\mathrm{Q}_{66}=G 12$

By utilizing the equations (5-15). The T, $\bar{C}$ and $Q$ matrixes for $30^{0}$ lay-up are obtained:

$$
[T]=\left[\begin{array}{cccccc}
0.7500 & 0.2500 & 0 & 0 & 0 & -0.8660 \\
0.2500 & 0.7500 & 0 & 0 & 0 & 0.8660 \\
0 & 0 & 1.0000 & 0 & 0 & 0 \\
0 & 0 & 0 & 0.8660 & 0.5000 & 0 \\
0 & 0 & 0 & -0.5000 & 0.8660 & 0 \\
0.4330 & -0.4330 & 0 & 0 & 0 & 0.5000
\end{array}\right]
$$




$$
[\bar{C}]=\left[\begin{array}{cccccc}
8.7271 & 2.8049 & 0.2259 & 0 & 0 & 4.4117 \\
2.8849 & 1.8838 & 0.8857 & 0 & 0 & 1.5147 \\
0.2259 & 0.0857 & 0.9711 & 0 & 0 & 0.1214 \\
0 & 0 & 0 & 0.3623 & 0.0299 & 0 \\
0 & 0 & 0 & 0.0299 & 0.3967 & 0 \\
4.4117 & 1.5147 & 0.1214 & 0 & 0 & 2.9229
\end{array}\right]
$$$$
\left[Q_{30^{0}}\right]=\left[\begin{array}{cccccc}
8.6745 & 2.7849 & 0 & 0 & 0 & 4.3835 \\
2.7849 & 1.8763 & 0 & 0 & 0 & 1.5040 \\
0 & 0 & 0 & 0 & 0 & 0 \\
0 & 0 & 0 & 0 & 0 & 0 \\
0 & 0 & 0 & 0 & 0 & 0 \\
4.3835 & 1.5040 & 0 & 0 & 0 & 2.9077
\end{array}\right]
$$

Similarly, T, $\overline{\mathrm{C}}$, and Q matrixes for 500 lay-up:

$$
\begin{aligned}
& {[T]=\left[\begin{array}{cc}
0.4132 & 0.5868 \\
0.5868 & 0.4132 \\
0 & 0 \\
0 & 0 \\
0 & 0 \\
0.4924 & -0.4924
\end{array}\right.} \\
& {[\bar{C}]=\left[\begin{array}{cc}
3.3817 & 3.5403 \\
3.5403 & 5.7584 \\
0.1315 & 0.1802 \\
0 & 0 \\
0 & 0 \\
2.7976 & 3.9417
\end{array}\right.} \\
& {\left[Q_{50^{0}}\right]=\left[\begin{array}{cccccc}
3.3639 & 3.5159 & 0 & 0 & 0 & 2.7789 \\
3.5159 & 3.3639 & 0 & 0 & 0 & 3.9161 \\
0 & 0 & 0 & 0 & 0 & 0 \\
0 & 0 & 0 & 0 & 0 & 0 \\
0 & 0 & 0 & 0 & 0 & 0 \\
2.7789 & 3.9161 & 0 & 0 & 0 & 3.6387
\end{array}\right]}
\end{aligned}
$$

Using the below equations to find the extensional stiffness matrix [A], coupling stiffness matrix [B], and bending stiffness matrix [D]:

$$
\mathrm{A}_{\mathrm{ij}}=\sum_{\mathrm{k}=1}^{3}\left[\overline{\mathrm{Q}}_{\mathrm{ij}}\right]_{\mathrm{k}}\left(\mathrm{h}_{\mathrm{k}}-\mathrm{h}_{\mathrm{k}-1}\right)
$$

$$
\mathrm{B}_{\mathrm{ij}}=\frac{1}{2} \sum_{\mathrm{k}=1}^{3}\left[\overline{\mathrm{Q}}_{\mathrm{ij}}\right]_{\mathrm{k}}\left(\mathrm{h}^{2}{ }_{\mathrm{k}}-\mathrm{h}^{2}{ }_{\mathrm{k}-1}\right)
$$

$$
\mathrm{D}_{\mathrm{ij}}=\frac{1}{32} \sum_{\mathrm{k}=1}^{3}\left[\overline{\mathrm{Q}}_{\mathrm{ij}}\right]_{\mathrm{k}}\left(\mathrm{h}^{3}{ }_{\mathrm{k}}-\mathrm{h}_{\mathrm{k}-1}^{3}\right)
$$

After utilizing equations (16), (17), and (18), we get:

$$
[A]=\left[\begin{array}{cccccc}
1.5289 & 0.8002 & 0 & 0 & 0 & 0.9096 \\
0.8002 & 0.9654 & 0 & 0 & 0 & 0.6884 \\
0 & 0 & 0 & 0 & 0 & 0 \\
0 & 0 & 0 & 0 & 0 & 0 \\
0 & 0 & 0 & 0 & 0 & 0 \\
0.9095 & 0.6884 & 0 & 0 & 0 & 0.8314
\end{array}\right]
$$

$$
\begin{gathered}
{[B]=\left[\begin{array}{cccccc}
-2.1414 & 0.2947 & 0 & 0 & 0 & 0.6470 \\
0.2947 & 1.5519 & 0 & 0 & 0 & 0.9726 \\
0 & 0 & 0 & 0 & 0 & 0 \\
0 & 0 & 0 & 0 & 0 & 0 \\
0 & 0 & 0 & 0 & 0 & 0 \\
-0.6470 & 0.9726 & 0 & 0 & 0 & 0.2947
\end{array}\right]} \\
{[D]=\left[\begin{array}{cccccc}
8.2198 & 4.3022 & 0 & 0 & 0 & 4.8904 \\
4.3022 & 5.1901 & 0 & 0 & 0 & 3.7008 \\
0 & 0 & 0 & 0 & 0 & 0 \\
0 & 0 & 0 & 0 & 0 & 0 \\
0 & 0 & 0 & 0 & 0 & 0 \\
4.8904 & 3.7008 & 0 & 0 & 0 & 4.4698
\end{array}\right]}
\end{gathered}
$$

One matrix for each due to that stiffness matrix [C] and compliance matrix [S] is not dependent on angles. Stiffness matrix [C] for angled lamina, transformation[T] and transformed reduced stiffness matrix [Q] these matrixes depend on angle, the numbers in these matrixes increased and decreased for $50^{\circ}$ and $30^{\circ}$ due to sine and cosine in their equations. Extensional stiffness matrix [A], coupling stiffness matrix [B], and bending stiffness matrix [D] is not depend on the angle as well as the stiffness matrix and compliance matrix.

\section{NUMERICAL ANALYSIS}

In this section comparison of natural frequencies of the laminated beam at different boundary conditions and lay-up angles Furthermore, a comparison of existing results with the presented study is evaluated.

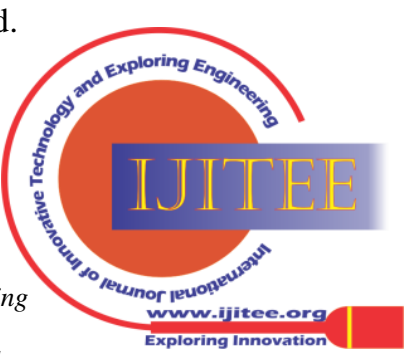


These values have been evaluated using ANSYS as shown in Appendix.

4.1 Case I, comparison between the existing study's results and this study's results of natural frequency:

Table 1. Natural frequencies $(\mathrm{Hz})$ three modes.

\begin{tabular}{|c|c|c|c|}
\hline Mode & S-S & C-S & C-C \\
\hline 1 & 294.8 & 450.5 & 638.6 \\
\hline 2 & 1132.4 & 1390.1 & 1658 \\
\hline 3 & 2414.7 & 2725.3 & 3036.2 \\
\hline
\end{tabular}

In Tables 2, the first three natural frequencies (Hz) of this study's results (as shown in Appendix) and the error between these results and the article's results.

Table 2. Natural frequencies (Hz), three modes of present study.

\begin{tabular}{|c|c|c|c|c|c|c|}
\hline Mode & S-S & Error \% & C-S & Error \% & C-C & Error \% \\
\hline 1 & 480.14 & 16.32 & 524 & 16.31 & 655.01 & 2.56 \\
\hline 2 & 1082 & -4.45 & 1466.2 & -5.47 & 1701.8 & 2.64 \\
\hline 3 & 2412.4 & -0.0952 & 2788.9 & -2.28 & 3119.6 & 2.74 \\
\hline
\end{tabular}

4.2 Case II, different angles of lay-up to observe the natural frequencies, they are $\left[0^{0} / 90^{0} / 0^{0} / 90^{\circ}\right],\left[0^{0} / 60^{0} / 0^{0} / 60^{\circ}\right]$, and $\left[0^{\circ} / 45^{\circ} / 0^{\circ} / 45^{0}\right]$ :

In Tables 3, the first six natural frequencies (Hz) of lay-up [00/900/00/900].

Table 3. Natural Frequencies of lay-up $\left[0^{0} / 9^{\circ} / 0^{\circ} / 9^{0}\right]$

\begin{tabular}{|c|c|c|c|}
\hline Mode & S-S & C-S & C-C \\
\hline 1 & 787.43 & 887.93 & 1022.7 \\
\hline 2 & 849.59 & 949.23 & 1127.4 \\
\hline 3 & 1795 & 1895.6 & 2390.9 \\
\hline 4 & 1859.2 & 2224 & 2677.7 \\
\hline 6 & 2187.2 & 2433 & 3897.6 \\
\hline
\end{tabular}

In Tables 4, the first six natural frequencies (Hz) of lay-up [00/600/00/600].

Table 4. Natural Frequencies of lay-up [00/600/00/600]

\begin{tabular}{|c|c|c|c|}
\hline Mode & S-S & C-S & C-C \\
\hline 1 & 827.32 & 890.13 & 1026.7 \\
\hline 2 & 851.3 & 1001 & 1193.7 \\
\hline 3 & 1797.1 & 2088.9 & 2180.5 \\
\hline 4 & 2032.5 & 2233.9 & 2405.2 \\
\hline 5 & 2365.4 & 2668.5 & 2950.6 \\
\hline 6 & 3845.5 & 3897.6 & 4066 \\
\hline
\end{tabular}

In Table 5, the first six natural frequencies (Hz) of lay-up [00/450/00/450].

Table 5. Natural Frequencies of lay-up $\left[0^{0} / 45^{0} / 0^{0} / 45^{0}\right]$

\begin{tabular}{|c|c|c|c|}
\hline Mode & S-S & C-S & C-C \\
\hline 1 & 860.77 & 901.63 & 1041.9 \\
\hline 2 & 861.09 & 1043.7 & 2357.7 \\
\hline 3 & 1811.9 & 2217.8 & 2436.7 \\
\hline 4 & 2174.4 & 2277.2 & 3159.8 \\
\hline 5 & 2491.2 & 2844.3 & 4114.1 \\
\hline
\end{tabular}

Published By:

Blue Eyes Intelligence Engineering and Sciences Publication

(C) Copyright: All rights reserved.

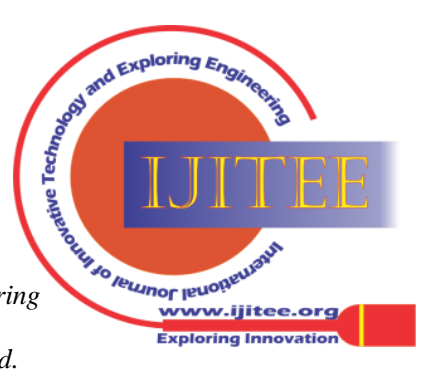




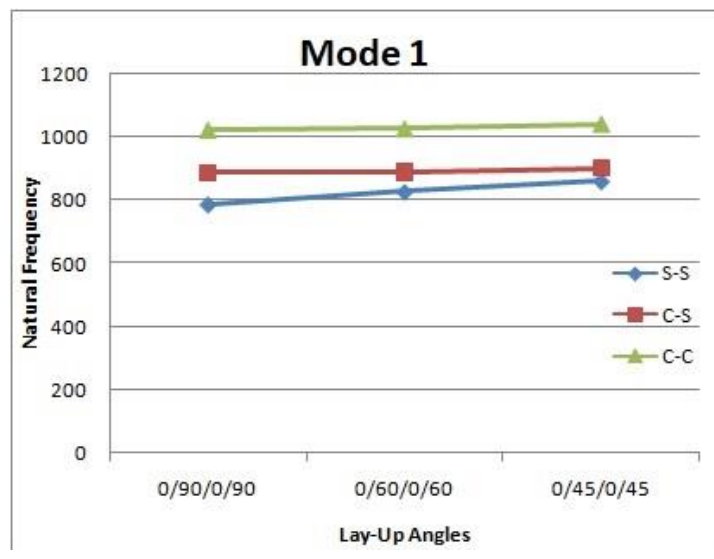

Fig 3. First mode shape of C-C, C-S, and S-S with lay-up $\left[0 \% 90^{\circ} / 0^{\circ} / 90^{\circ}\right],\left[0^{\circ} / 60 \% \% / 60^{\circ}\right]$ and $\left[0 \% 45^{\circ} / 0^{\circ} / 45^{\circ}\right]$

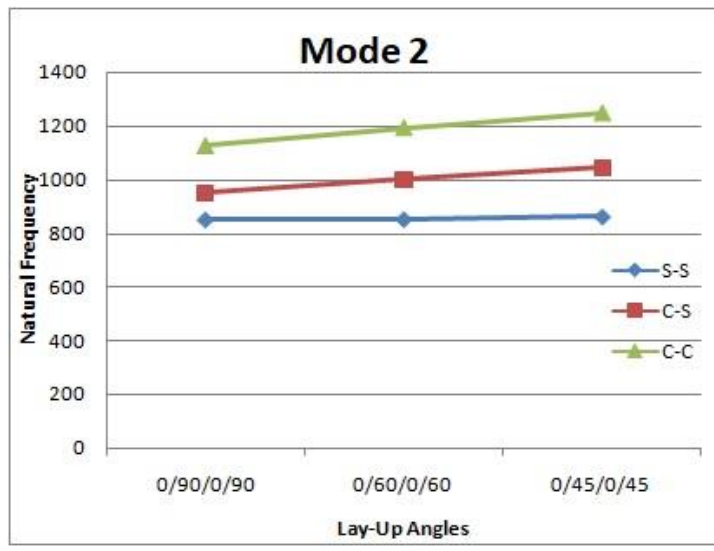

Fig 4. Second mode shape of C-C, C-S, and S-S with lay-up $\left[0 \% / 90^{\circ} / 0^{\circ} / 90^{\circ}\right],\left[0 \% / 60 \% \% / 60^{\circ}\right]$ and $\left[0 \% / 45^{\circ} / 0^{\circ} / 45^{\circ}\right]$

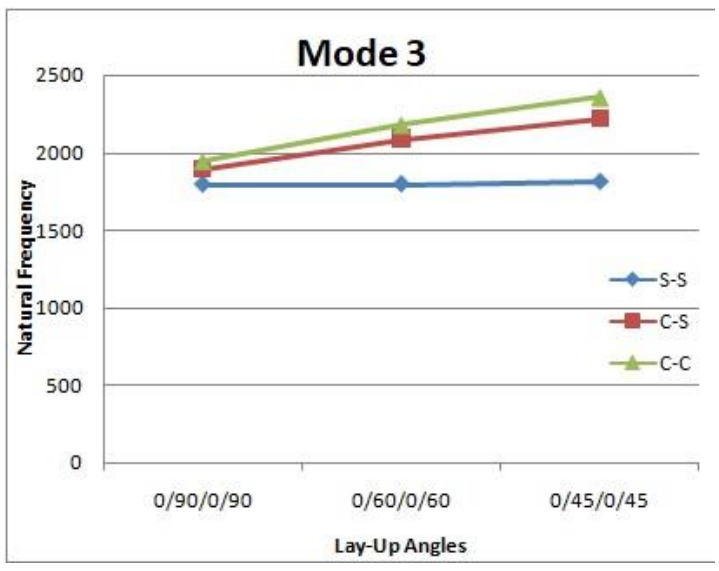

Fig 5. Third mode shape of C-C, C-S, S-S

with lay-up $\left[0^{\circ} / 90^{\circ} / 0^{\circ} / 90^{\circ}\right],\left[0^{\circ} / 60^{\circ} / 0^{\circ} / 60^{\circ}\right]$ and $\left[0 \% / 45^{\circ} / 0^{\circ} / 45^{\circ}\right]$

After getting the values of natural frequencies with layup of $\left[0^{0} / 90^{\circ} / 0^{0} / 90^{0}\right],\left[0^{0} / 60^{\circ} / 0^{0} / 60^{0}\right]$, and $\left[0^{\circ} / 45^{\circ} / 0^{\circ} / 45^{0}\right]$ at different boundary conditions C-C, C-S, and S-S. Then converted these values to diagrams, to see the relation between the values of natural frequencies and the angles of lay-up, as shown in Fig 3, Fig 4, and Fig 5. In mode1, the changing of lay-up's angle shows that no affected on natural frequency. Mode 2 displays that the changing of natural frequency is due to changing of lay-up angles at the second layer, especially with C-C and C-S while S-S has a small changing of values. So, mode 2 tells that when increasing the difference between angles of lay-up the values of natural frequency are decreased. Mode 3 is almost the same as mode 2 , just that the changing of the natural frequency with $\mathrm{S}-\mathrm{S}$ is bigger than $\mathrm{S}-\mathrm{S}$ at mode 2.

4.3 Case III, changing lay-up angles to be [300/900/300/900] and compare it with [00/600/00/600]:

In Tables 6 , the first five natural frequencies of lay-up $\left[30^{\circ} / 90^{\circ} / 30^{\circ} / 90^{\circ}\right]$.

Table 6. the first five natural frequencies of lay-up $\left[30^{0} / 90^{0} / 30^{0} / 9^{0}\right]$

\begin{tabular}{|l|l|l|l|}
\hline Mode & \multicolumn{1}{|c|}{ C-S } & \multicolumn{1}{c|}{ C-C } \\
\hline 1 & 458.26 & 502.25 & 626.24 \\
\hline 2 & 511.35 & 582.57 & 663.74 \\
\hline 3 & 1035.6 & 1386.2 & 1600.8 \\
\hline 4 & 1454.9 & 1606 & 1779.4 \\
\hline 5 & 2116.2 & 2223.4 & 2347.3 \\
\hline 6 & 2465.2 & 2608.4 & 2888.1 \\
\hline
\end{tabular}

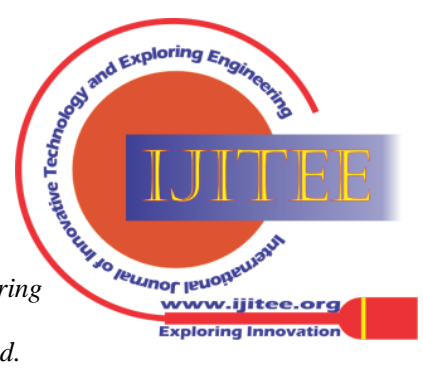




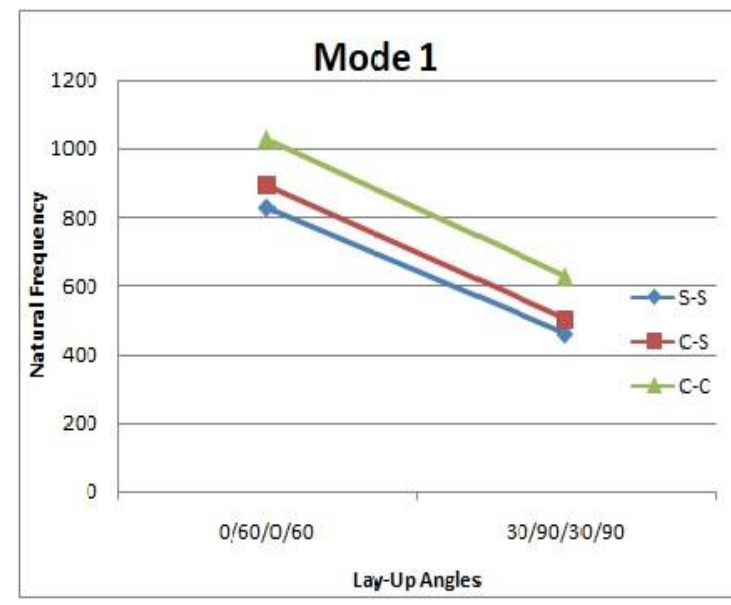

Fig 6. First Mode shape with lay-up angle $\left[0 \% / 60^{\circ} / 0^{\circ} / 60^{\circ}\right],\left[30^{\circ} / 90^{\circ} / 30^{\circ} / 90^{\circ}\right]$.

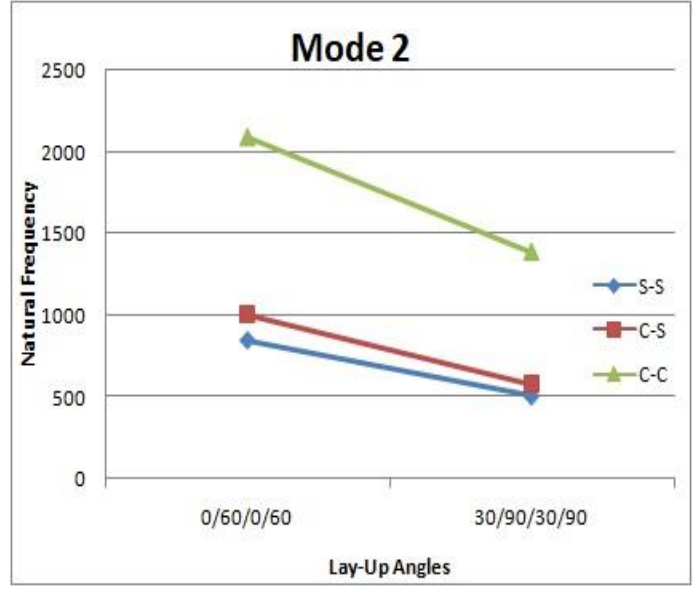

Fig 7. Second mode shape with lay-up angle $\left[0 \% 60 \% \% / 60^{\circ}\right],\left[30 \% / 90^{\circ} / 30^{\circ} / 90^{\circ}\right]$

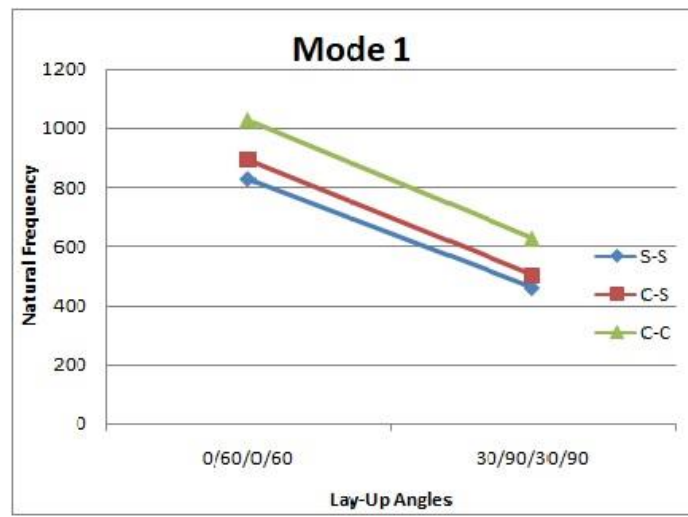

Fig 8. Second mode shape with lay-up angle $\left[0^{\circ} / 60^{\circ} / 0^{\circ} / 60^{\circ}\right],\left[30^{\circ} / 90^{\circ} / 30^{\circ} / 90^{\circ}\right]$.

The point of this case is to observe the values of the natural frequency with the same difference of the angles between the layers $\left(60^{\circ}\right)$, just lay up the first layer at a different angle $\left(0^{0}, 30^{\circ}\right)$. Fig 6 , Fig 7 , and Fig 8 show that the values of the natural frequency with lay-up of $\left[0^{\circ} / 60^{\circ} / 0^{\circ} / 60^{\circ}\right]$ and $\left[30^{\circ} / 90^{\circ} / 30^{\circ} / 90^{\circ}\right]$ at different boundary conditions C-C, $\mathrm{C}-\mathrm{S}$, and S-S. At mode 1, mode 2, and mode 3 there are changes of the values between lay-up of $\left[0^{\circ} / 60^{\circ} / 0^{0} / 60^{\circ}\right]$ and $\left[30^{\circ} / 90^{\circ} / 30^{\circ} / 90^{0}\right]$. lay-up of $\left[0^{\circ} / 60^{\circ} / 0^{\circ} / 60^{\circ}\right]$ has a bigger value at mode 1 and mode 2 than lay-up of $\left[30^{\circ} / 90^{\circ} / 30^{\circ} / 90^{0}\right]$, while at mode 3 lay-up of $\left[30^{\circ} / 90^{\circ} / 30^{\circ} / 90^{\circ}\right]$ has a larger value but the difference is not much. So, that means that the angle of the first lay-up plays a vital role in effect natural frequency as well as the difference between the angles of layers.

\section{CONCLUSION}

In this paper, the free vibration of laminated composite beams has been studied. The finite element method has been used to predict the natural frequencies, and the influence of lay-up angles of composite materials on the natural frequencies has been considered. Three different boundary conditions were selected in this study, they are ClampedClamped (C-C), Clamped-Simply supported (C-S), and Simply supported-Simply supported $(\mathrm{S}-\mathrm{S})$. The main conclusions are that the values of natural frequency decreased when increased the difference between angles of lay-up, and the angle of the first lay-up plays a vital role as well as, the difference between the angles of layers while the difference between angles is the same.

\section{REFERENCE}

1. Li, J., Wu, Z., Kong, X., Li, X., \& Wu, W. (2014). Comparison of various shear deformation theories for free vibration of laminated composite beams with general layups. Composite Structures,108, $767-$

2. doi:10.1016/j.compstruct.2013.10.011 Abramovich, H., Shear deformation and rotary inertia effects of vibrating composite beams. CompositeStructures, 1992. 20(3): p. 165-173

3. Teoh, L. and C.-C. Huang, The vibration of beams of fibre reinforced material. Journal of Sound and Vibration, 1977.51(4):p. 467-473

4. Abramovich, $\mathrm{H}$. and A. Livshits, Free vibrations of nonsymmetric cross-ply laminated composite beams. Journalof sound and vibration, 1994. 176(5): p. 597-612

5. Teboub, Y. and P. Hajela, Free vibration of generally layered composite beams using symbolic computations.Composite structures 1995. 33(3): p. 123- 134

6. Ghugal, Y. and R. Shimpi, A review of refined shear deformation theories for isotropic and anisotropic laminated beams. Journal of reinforced plastics and composites, 2001. 20(3): p. 255-134

7. Marur, S.R. and T. Kant, Transient dynamics of laminated beams: an evaluation with a higher-order refinedtheory of Composite structures, 1998. 41(1): p. 1-11

8. Lee, J., Free vibration analysis of delaminated composite beams Computers \& Structures, 2000. 74(2): p. 121-129

9. Li, J., et al., Comparison of various shear deformation theories for free vibration of laminated composite beams with general lay-ups. Composite structures, 2014. 108: p. 767-778

10. Kapania RK, Raciti S. Recent advances in analysis of laminated beams and plates: Part I. Shear effects and buckling; Part II Vibrations and wave propagation. AIAA J 1989;27:923-46.

Published By:

Blue Eyes Intelligence Engineering

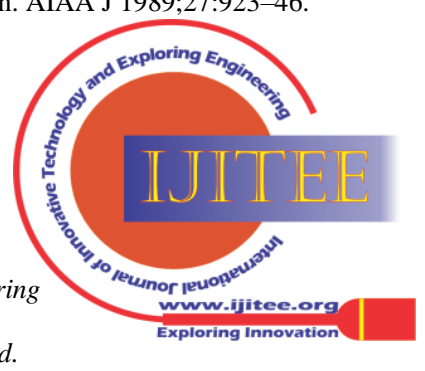


11. Chen AT, Yang TY. Static and dynamic formulation of symmetrically laminated beam finite element for microcomputer. J Compos Mater 1985;19:459-75.

12. Teh KK, Huang CC. The vibrations of generally orthotropic beams, a finite element approach. J Sound Vib 1979;62

\section{AUTHORS PROFILE}

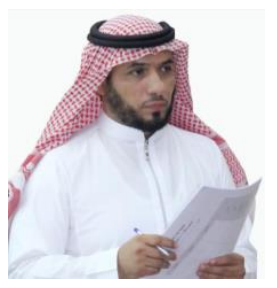

Dr. Asiri's, research activities are on the vibration control of mechanical systems. He and his advisor, Prof. A. Baz, have innovated a new class of support struts called periodic struts as an isolator of the mechanical vibrations. He presented the innovative use of unique characteristics of periodic struts in many critical applications where the control of the wave propagation and the force transmission both in the spectral and spatial domains is essential to stopping/confining the propagation of undesirable disturbances. He got in 2010 a patent from KACST titled: Differential Agitator and a patent from US Patents titled: Smart Boat for Swimming Pool Maintenance and Water Safety. Dr. Asiri currently teaches vibrations and control courses for undergraduate and graduate students. In addition, he published lately many papers on vibration analysis and modal analysis of Functionally Graded Materials using FEM.

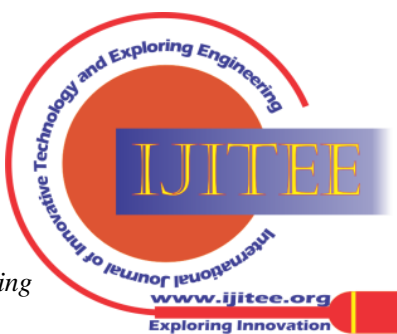

